\title{
On the Teaching Reform of Hydromechanics Course
}

\author{
Jun $\mathrm{Guo}^{1}$, Xingguo Guo ${ }^{2}$ \\ ${ }^{1}$ College of Civil Engineering and Architecture, Jiujiang University, Jiujiang, 332005, China \\ ${ }^{2}$ Nanchang University, Nanchang, 330031, China
}

Keywords: Hydromechanics. Teaching Reform. Teaching Method

\begin{abstract}
Hydromechanics course in university is strongly theoretical. And many students feel so difficult to understand and master that they produce the mood of study-weariness. So, in the teaching of hydromechanics course, measures should bu taken to reform it to keep pace with the times. This article explores the hydromechanics teaching from the following aspects: illustration teaching methodology, heuristic teaching methodology, practice-oriented teaching methodology and multimedia teaching methodology.
\end{abstract}

\section{Introduction}

Hydromechanics, one of the important basic courses of engineering majors in universities, is a course which mainly researches the flux balance and its movement rules. Because of its strong theory, and confusing, it is difficult for teachers to teach and students to understand. So, it is very necessary to reform the teaching, improve the teaching quality and students' innovation and lay a good foundation for further study.

\section{Illustration teaching method}

In hydromechanics teaching, teachers should prepare their teaching carefully to give a successful lesson and thus improve their teaching capability. Teachers should not only teach knowledge, but also the scientific methods, minds and spirit and combine the two perfectly as much as possible. Considering this, preparing lessons and collecting and rectify materials is very important. At the same time, teachers should combine theory and practice to make the lessons teaching more effective. For example, when explain pressure is a scalar you can take an example that when a diver dive to a absolute deep, the pressure his face faces in all direction is the same. This manner which combines the theory with practice can make students feel that theory is not rigid or abstract formulas but a useful tool that can solve the practical problems. By this course, students master the scientific theory instead of formulas or regularities.

\section{Heuristic Teaching Methodology}

Heuristic teaching is common method. In hydromechanics, teachers should invent a concrete a heuristic teaching methods suitable for this course based on its content and students' study regularity.

One is the introduction of contrast heuristics. In the course of hydromechanics, using comparative heuristic teaching mainly covers the following three parts. First, compare the similar or contrary definition or concept of hydromechanics to make the system clearer and inspire students' thinking and memory. For example, in the introduction of Eulerian method and Lagrangian method, streamline and trace and laminar and turbulent, steady and unsteady flow, teachers should pat attention to inspire students to contrast. Second, it is important to compare the old and new knowledge for students to master the new knowledge and skills faster. There is another example, teachers can analysis and compare the formulas of the ideal origin Bernoulli equation, the total flow Bernoulli equation and the actual fluid Bernoulli equation, so the students can better understand it. Third, the theoretical knowledge and practical application should be compared to make the abstract specific and thus deepen the students' perceptual knowledge. For example, after explaining the 
continuity equation and Bernoulli equation, its application should in the engineering practice of orifice and the nozzle flow should also be calculated, so that the students can digest the theoretical knowledge.

Then is the enlightenment step by step. Hydromechanics is a practical course. Because it not only comes in practice, but also applies to practice and is closely related to our life. This feature allow students to apply theory to practice and deepen their understand. For example, from a tornado we can lead to the natural phenomenon of spiral flow; from two collided ships, we can bring in Bernoulli equation, etc. In this way, we can properly combine the life experience with theoretical knowledge. It not only can enhance the learning enthusiasm of students, but also can help them overcome the boring feeling in theoretical study and also can guide students step by step to deepen their understanding from analysis to solve the problem. By this improvement step by step teaching, we can improve the effect of classroom teaching in the maximum limit.

Third is to develop a kind of discussion-based inspiration. As an important teaching manner, it combines study and thinking, study and discussion. It is also an student-oriented teaching method under the guidance of teachers. When adapting this method, teachers must be careful to selects topics. The selected topics should be helpful to understand the basic concepts and increase the delight of classes. At the same time, discussion among students should be organized. During this process, teachers should actively coordinate the atmosphere of the class discussion and guide the students to debate and avoid deviating from the teaching content. Of course, in the final stage, the instructor should give a summary of the in time, fully affirmed the right opinion, and praise those creative ideas and insights and emphatically points out the cause of the error argument. As a result, not only the cognitive competence but also the thinking methods be promoted. In the process of teaching, I often guide college students to think and discuss after explain a certain knowledge point. For example, after giving a lecture of Bernoulli equation, I will invite students to think and discuss some questions. For example, what is the principle of "banana ball" in the football match? Why do the golf clubs have a pit and why do geese row of herringbone? From the perspective of the effectiveness of teaching, the classroom discussion can create a very vivid and lively scene, so that the students can grasp the contents better in the process of participating and also can cultivate their innovation spirit.

Fourth, heuristics of classroom practice. Because hydromechanics is a strongly theoretical discipline and the abstract concept and equation can be found everywhere, in fluid mechanics classroom exercises training has become a necessary manner for college students to deepen their understanding and consolidate the knowledge. On the arrangement of the training topic, teachers should choose typical, comprehensive and practical subject. For the part of teaching difficulty, teachers should let the students discuss with each other based on the inspiration. Therefore, students can understand gradually and get the answer in the process of debate. The most important thing is that at the end of the training teachers and the students had better get together to conclude the emphases and difficulties and key points of training topic. Thus scientifically sums up the rules and steps of problem solving. It proves that classroom exercises training, inspiration and summary can more effectively make engineering students consolidate the knowledge, and promote their study enthusiasm.

\section{Practice-oriented Teaching Methodology}

Choose some common phenomenon in our daily life and combine them with teaching. As long as we observe carefully, we can find many phenomenon concerned with hydromechanics. So when introducing relative concepts, we can bring forth some phenomenon to help students understand the knowledge. For example, for the liquid surface tension, it is a one of the specialized physical phenomena of the curved liquid surface. The teacher can take an example in our daily life that the water in narrow gap will not pour out. In this way students can do the fluid mechanics experiment easily after classes. For example, put a dry coin or pin light on calm water without sinking and let the students observe surface shape of coins and pin to help them understand the phenomenon of surface 
tension. What's more, teachers can interpret the meaning of lift by means of rotating football or table tennis. That the track is a curve is the result of lift.

Using famous persons and events to assist teaching. Teachers can introduce some famous scientists who have make great contribution to hydromechanics. It can not only inspire undergraduates and increase their study initiative but also can indirectly implement humanistic education and patriotism education. For example, in the introduction of the fluid mechanics, when a teacher points out that the development of fluid mechanics in our country has a long history, he can introduce the famous hydraulic engineering in Sichuan Minjiang river-Dujiangyan Water Conservancy Project. Build in 256 BC, it is the world's most ancient project which divert and irrigate by no dams. And it is can also be used to irrigate and control flood. It is marvels been build in the command of Li Bing. It can effectively strengthen students' patriotic sentiment, and make them preliminary realize the importance of fluid mechanics in engineering. As another example, in the process of interpretation of flow pattern criterion Reynolds number, it can be divided into three steps to introduce Renault. First, Renault was born in 1842, the British. At twas still at that time Britain was in first industrial revolution, while China is in the First Opium War. Based on the contrast to the rapid progress of industrial revolution and the cruelty of aggressive war, it can be concluded that the science and technology is backward in our country, thus to inspire students' learning enthusiasm and devotion. Second, Renault is an expert on mechanics as well as an engineer. It points out the importance of engineers, so that students can be full of confidence about their future. What's more, Renault is also an important experiment scientists. However, because the physical experiment condition is quite limited at that time and the university Renault was in didn't have laboratory, a large number of his early experiments were completed in his own home. Through a detailed explanation of such persons and event, students will learn to love their life and work. In order to further enhance the atmosphere of the classroom, the teacher can also do a distinction between this Renault and another Renault.

\section{Multimedia Teaching Methodology}

Multimedia mainly refers to the combination of text, images, audio and video and many other media forms. At present, multimedia is a kind of medium that combines words, animation, video and audio and so on. In university, it is beneficial for students to understand the generate of flow phenomenon by using multimedia teaching method. Besides, it can improve their enthusiasm of learning. However, when doing summery and communicating with students, I found that using too much multimedia information can produce adverse effect. For example, college students may only focus on those wonderful animation works and neglect the fluid mechanics theory knowledge in the course of learning; it takes so much time to play and interpret the multimedia courseware that it affects the teaching schedule; On one hand, multimedia teaching can save time compared to the traditional blackboard writing teaching need so as to increase the capacity of the fluid mechanics teaching. But on the other hand, with the speeding up of the teaching, students' may fail to understanding and digest so much new knowledge. So, multimedia courseware should be control to a proper degree. The problem can be solved from the following three aspects. First, choose a small number of multimedia data that combined closely with the teaching content. It is the quality not the quantity that matters; Second, once the students addicted to wonderful multimedia images, the teacher should timely use proficient skills to drag the students out of the artistic conception and come back to the class; Third, keep an eye on the speed of teaching, so as to set aside enough time for students to understand.

\section{Conclusion}

Above all, the hydromechanics course in universities is strongly theoretical and difficult to learn. It needs the effort of both teachers and students to make it a good principle. Teachers should create conditions to make every students release their potentials as much as possible. So, carrying out 
various forms of teaching methods can help students to cultivate their ability and arouse their learning initiative. At the same time, much attention should be paid to combine life with work experience, so that the students can understand how to apply the theory of fluid mechanics to the practice. Thus the goal of learning can become stronger and the teaching can yield twice the result with half the effort.

\section{References}

[1] Mo Nairong: Engineering Hydromechanics, Wuhan:Huzhong University of Science and Technology Press, 2009.

[2] Wu Guanglin: The Research of Hydromechanics, Scientific Information,2008(14).

[3] Yue Jianzhi: The Rsearch of Hydromechanics Teaching, Scientific Information, 2008 (29).

[4] Hao Jianli: A Brief Analyses of Hydromechanics Teaching Reform, Shanxi Construction, 2010(26). 